\title{
Nutrition intervention in ethnic minority groups
}

\author{
Jane Thomas \\ Department of Nutrition and Dietetics, King's College London, London SE19NN, UK
}

\begin{abstract}
Development of effective intervention strategies to meet the needs of people with ethnic minority origins is dependent on two factors: an understanding of the modifiable risk factors which can form the basis of intervention; an understanding of the relevant health behaviours so that appropriate strategies can be designed. The present paper briefly reviews the evidence concerning the part that nutritional and dietary factors play in the aetiology of the observed patterns of disease in these groups and the limitations of the data as a basis for intervention. Consideration is also given to the available information concerning factors influencing health behaviour (particularly eating behaviour) and the applicability of commonly-used models of behaviour change to people of ethnic minority origin. Finally, the results of nutrition intervention programmes will be examined with a view to identifying lessons for the future.
\end{abstract}

Ethnic minority groups: Intervention strategies: Modifiable risk factors: Health behaviour

Large-scale migration into the UK from non-European countries has been primarily a phenomenon of the second half of the twentieth century, and the current composition of the population reflects the successive waves of migration from different locations. Not only the locations, but also the stimulus to migration, have varied during these 50 years. The impetus for migration has been both a 'pull' and 'push' phenomenon. Initial arrivals were invited to help meet manpower shortages after the Second World War and to rebuild Britain. Subsequent groups were responding to changing situations in their home countries that made a move to the UK seem attractive; for example: the changes in the New Territories in the 1960s which stimulated the migration of many Hong Kong Chinese to the UK and fuelled the growth of the Chinese restaurant trade; the Bangladesh War; the activities of Idi Amin and the driving out from East Africa of many families of South Asian origin. The reasons for relocation, the continuing ties with the country of origin and orientation towards the future, whether these immigrants see themselves as sojourners or new citizens, clearly have implications for many aspects of lifestyle choice and behaviour, including eating habits and diet.

These patterns of migration and other social factors are reflected in the profiles of the different groups within the UK population. As Table 1 indicates, the proportion over retirement age is lower in all groups than in the white population, while about half the population of Bangladeshi origin in the 1991 census were aged $<15$ years. It is also increasingly important to take into account inter-generational differences in these groups. In the 1991 census more than half those who were of black Caribbean origin and about one-third of those of Indian origin had been born in the UK (Warnes, 1996). With > 1.5 million people representing the second and third generation in these ethnic groups, the need to understand the processes which underlie their experience of health and disease are clearly an important issue for public policy.

Development of effective intervention strategies to meet the needs of people with ethnic minority origins is dependent on two factors:

an understanding of the modifiable risk factors which can form the basis of intervention;

an understanding of the relevant health behaviours so that appropriate strategies can be defined.

\section{Health, disease and diet}

Awareness of health issues in ethnic minority communities in the UK has been shaped by the history of the migration process and our changing understanding of the aetiology of disease.

Migration for work is usually undertaken by fit young adults, predominantly men, who initially place relatively small demands on the health services in the host community. 
Table 1. Distribution of the population in the UK by ethnic group and age (CSO, 1994)

\begin{tabular}{lcccccc}
\hline Age-group (years) & $\begin{array}{c}0-15 \\
(\%)\end{array}$ & $\begin{array}{c}16-29 \\
(\%)\end{array}$ & $\begin{array}{c}30-44 \\
(\%)\end{array}$ & $\begin{array}{c}45-49 \\
(\%)\end{array}$ & $\begin{array}{r}60+ \\
(\%)\end{array}$ & $\begin{array}{c}\text { All ages } \\
\left(\times 10^{3}\right)\end{array}$ \\
\hline Black Caribbean & 21.9 & 7.6 & 20.0 & 19.6 & 10.9 & 500 \\
Indian & 29.5 & 23.9 & 25.9 & 13.8 & 6.8 & 840 \\
Pakistani & 42.6 & 24.0 & 19.2 & 10.4 & 3.7 & 477 \\
Bangladeshi & 47.2 & 23.3 & 14.8 & 11.4 & 3.3 & 163 \\
Chinese & 23.3 & 29.7 & 29.4 & 12.0 & 5.7 & 157 \\
All ethnic minorities & 33.0 & 26.0 & 22.6 & 12.6 & 5.8 & 3015 \\
White & 19.3 & 20.4 & 21.2 & 17.0 & 22.1 & 51874 \\
\hline
\end{tabular}

The later arrival of wives and children to join the initial migrants, and families who arrive under straightened circumstances, may represent more vulnerable groups.

This pattern has been reflected in the UK experience. Following the first report of rickets and osteomalacia in the Asian community in Glasgow in 1962 (Dunnigan et al. 1962), subsequent studies indicated that vitamin D deficiency was not only a problem in infancy, but also thoughout childhood and in adult women, prompting a government report (Department of Health and Social Security, 1980) and the 'Stop Rickets' Campaign (Dunnigan et al. 1985). Infantile rickets and Fe-deficiency anaemia were reported in a smaller proportion of Afro-Caribbean children. However, poor vitamin $\mathrm{B}_{12}$ and folate status, Fe-deficiency anaemia and megaloblastic anaemias in infants and children, and during pregnancy, were reported in a number of South Asian communities during the 1970s and 1980s (Robertson et al. 1982; Eaton et al. 1984; Wharton et al. 1984).

As migrant communities matured, other health problems emerged. The Southall Diabetes Survey (Mather \& Keen, 1985), and subsequent work that identified elevated rates of diabetes and cardiovascular disease (Balarajan et al. 1984; Balarajan, 1991) in people of South Asian and AfroCaribbean origin, raised questions about risk factors in adult members of these communities. We have yet to see unfold the experience of diet-related disease among elderly members of ethnic minority groups.

At the same time our understanding of the aetiology of health problems in middle age increasingly points back to nutritional experiences in early life. The increasing emphasis on the effects of nutrition on birth outcomes and the effects of birth weight and diet in early childhood on subsequent patterns of disease (Barker, 1997) have re-focused attention on the effects of diet during pregnancy and early life, and on patterns of growth. These factors may be of particular importance in relation to members of ethnic minority communities. Concerns about the relationship between nutrition and health in these groups have in some ways come full circle.

\section{Identifying modifiable risk factors}

In exploring these relationships it is essential to take account of the heterogeneity within ethnic groups, inter-generational differences, the limitations of our knowledge of dietary intake and food composition, and the interaction between risk factors.
Diet-related factors are only one element contributing to the different health experiences of members of ethnic minority groups. The impact of socio-economic differences is increasingly recognised as providing a crucial overarching role in explaining the differences between minority groups and the majority, and also the different health experiences between members of different ethnic minorities.

Recent findings (Nazroo, 2001), based on morbidity data from the Fourth National Survey (Smith \& Prior, 1996), suggest that socio-economic factors may contribute to the observation that sub-ethnic groups within the South Asian community in Britain do not share a uniformly greater risk of heart disease. Socio-economic position predicted risk within each ethnic group, and made a key contribution to the higher risk found for people of Pakistani and Bangladeshi origin.

In seeking explanations for these patterns of disease Nazroo (2001) suggests that greater consideration needs to be given to the inter-relationships between risk factors, particularly the importance of environmental triggers for genetic risk and the possibility that biological markers may be the consequence of environmental exposure rather than genetic risk.

Studies have shown that the risk of ill-health in adulthood is linked to the length of time spent in a disadvantaged state over the life course (Davey-Smith et al. 1997; Kuh \& Ben-Shlomo, 1997). Social mobility, or lack of it, may therefore also play a part in explaining trends in different ethnic minority groups. Although the study by Harding \& Balarajan (2001) that linked mortality data with information from the Office for National Statistics Longitudinal Study (Hattersley \& Creeser, 1995) indicated considerable upward social mobility, most people from ethnic minorities remained relatively socially stable and mainly relatively socially disadvantaged. Drawing attention to the high levels of unemployment and unskilled employment among people of African, Caribbean, Bangladeshi and Pakistani origin in the 1991 census, the authors suggest that this disproportionate disadvantage does not bode well for the future, either for migrants or their children, who will suffer the consequences of parental disadvantage. In particular, the impact of income on birth weight across generations may have consequences of particular concern in relation to deprivation and patterns of CHD in ethnic minority groups. Basing their work on inter-generational data from the Panel Study of Income Dynamics in the USA (survey years 1968-92), Conley \& Bennett (2001) have demonstrated that maternal income has a marked effect on birth weight for those infants who are already at high risk hereditarily (i.e. have one low-birth-weight parent). Furthermore, the negative impact of low birth weight on high-school graduation was substantial, thereby contributing to a continuing cycle of poor economic opportunities.

\section{The role of diet}

Reflecting on the picture which is emerging concerning the role of diet in the health experience of two of the largest ethnic minorities in the UK (South Asians and AfroCaribbeans), it appears that it may be possible to identify certain common strands which might form a basis for intervention, much as the focus on fat, fibre, sugar and salt was 
justified in relation to a variety of associations in the original Working Party of the National Advisory Committee on Nutrition Education (1983) report. Thus, attention to particular aspects of diet may result in benefits in relation to avoidance of deficiency, but also moderation of a number of health risks that appear to be greater in these communities in the UK.

\section{Low birth weight}

Growing concern about the role played by nutrition in the early stages of life may be particularly relevant to health concerns among ethnic minority communities. Perinatal mortality is generally higher among infants of mothers born in New Commonwealth countries. Raleigh \& Balarajan (1995) observed that perinatal mortality rates in England and Wales for infants of mothers born in Pakistan (14.2 per 1000 total births) was almost double the rate of the UK-born group.

Birth weight is probably the single most important factor affecting neonatal mortality. Differences in birth weight between South Asian and Caucasian infants were reported by Kramer (1987), who found a mean birth weight of $2770 \mathrm{~g}$ (27\% with low birth weight) among Pakistani infants and $3310 \mathrm{~g}$ (7 \% with low birth weight) for Caucasian infants. Despite some increase in birth weights, Pakistani mothers continue to be more likely to have lighter babies than Caucasians, even when mothers were born in the UK (Raleigh \& Balarajan, 1995).

Many factors are associated with low birth weight, including income (as indicated earlier), but two dietary factors that may be of particular concern in relation to the South Asian community in the UK are Fe and vitamin D status.

$\mathrm{Fe}$ deficiency and Fe-deficiency anaemia are the most prevalent nutrient deficiency problems affecting pregnant women, and the prevalence of poor Fe status amongst women of South Asian origin in the UK has been widely documented (Steer et al. 1995). A number of studies have reported an association between Fe deficiency and low birth weight (Murphy et al. 1986; Kramer, 1987; Scholl \& Hediger, 1994; Lops et al. 1995; Thame et al. 1997). Findings from a study undertaken in one London Hospital (Hyder, 1999) suggest that this concern may be justified. All birth records ( $n$ 3077) for 1 year, 1997, were checked for births to mothers of Pakistani origin ( $n$ 323) and matched with data for Caucasian mothers of the same age and parity ( $n$ 563). The mean birth weight was markedly higher for Caucasian infants $(3.46 \mathrm{~kg})$ than for those of Pakistani origin $(3.16 \mathrm{~kg})$, and $9.6 \%$ of the Pakistani mothers gave birth to low-birth-weight infants $(<2.5 \mathrm{~kg})$ compared with $3.6 \%$ of the Caucasian mothers. In the second trimester, the mean haemoglobin level of mothers of Pakistani origin (1.12 g/l) was significantly lower than that of Caucasian mothers $(1.16 \mathrm{~g} / \mathrm{l} ; P<0.002)$.

There has been longstanding concern about the vitamin D status of members of the South Asian community in the UK (as indicated earlier), but rickets and osteomalacia may not be the only associated health problems. Many factors are associated with low birth weight. However, on the basis of studies among African-Americans, Fuller (2000) presents an interesting argument that inadequate levels of serum vitamin D during gestation can cause foetal growth problems leading to small-for-gestational-age infants. Fuller (2000) highlights the influence of skin pigmentation and the phenotype-environment interaction that she argues leads to u.v. deprivation at northern latitudes and contributes to observed differences in birth weight between white and black Americans (controlling for maternal characteristics and socio-economic status). Fuller (2000) also cites data from UK studies indicating exceptionally low levels of vitamin D among South Asian women in the last trimester of pregnancy, approximately one-third of whom had undetectable levels of 25-hydroxycholecalciferol. Furthermore, South Asian women who were supplemented with $25 \mu \mathrm{g}$ vitamin D/d had $50 \%$ fewer low-birth-weight babies. There is also a possibility of generational effects associated with reduced pelvic capacity among women, due to inadequate vitamin D status in early life, which increases the risk of subsequently giving birth to low-birth-weight babies.

There is continuing evidence of low 25-hydroxycholecalciferol levels (Lawson \& Thomas, 1999) in South Asian children, and this evidence, together with a possible role in low birth weight and hypertension, suggest that vitamin D intake would be an aspect of diet requiring particular attention among members of the South Asian and Afro-Caribbean communities.

\section{Diabetes and cardiovascular disease}

Cardiovascular disease is the most common cause of death in the UK, and the risk of premature disease varies according to ethnic group. Relative to the white population, Afro-Caribbeans have a high incidence of stroke (Balarajan, 1991) and end-stage renal failure (Roderick et al. 1994; Raleigh, 1997), whereas CHD is less common. South Asians have a higher incidence of CHD (Balarajan, 1991), and both groups are more at risk of diabetes (Cappuccio et al. 1997) than Caucasians. As a result a need for interventions which target hypertension, diabetes and CHD has been identified.

However, as Bhopal et al. (1999) point out, there is a need to take account of sub-ethnic variations in risk-factor profiles within the South Asian community. While high blood pressure is an important risk factor among Europeans and Indians, poverty and smoking appear to be more important among Pakistanis and Bangladeshis. In all groups of South Asians central obesity, lack of exercise and insulin resistance are important, and this study also supports a role for infant deprivation (all South Asians were shorter).

The insulin resistance syndrome hypothesis has dominated consideration of the modifiable risk factors for CHD since McKeigue \& Saver (1994) and other workers demonstrated that 'classic risk factors' failed to explain the high rates of mortality and morbidity from CHD in South Asian groups. A number of metabolic abnormalities are associated with insulin resistance (Hauner, 2002): impaired glucose tolerance; high triacylglycerol levels; low HDLcholesterol levels; smaller denser LDL particles; enhanced postprandial lipaemia; increased serum uric acid levels; elevated plasminogen activator inhibitor-1 levels. There seems little doubt that lifestyle factors are important 
determinants of insulin resistance, and consequently metabolic syndrome. Identification of the factors that are amenable to change is therefore an important prerequisite for intervention.

The effect of dietary factors on insulin resistance is complex and controversial, but there is evidence to support a role for obesity and weight gain, as well as the type and amount of dietary fat and fibre.

\section{Weight gain}

Some recent studies have clearly indicated that weight gain is followed by the development of metabolic syndrome. Weight gain from the age of 7 years is related to serum insulin and lipid levels as well as systolic blood pressure in early adulthood (Sinaiko et al. 1999). A study from Finland (Everson et al. 1998) found that weight gain from early adulthood to middle age is also associated with an increased risk of developing the insulin resistance syndrome (Everson et al. 1998).

A number of studies have observed the risks associated with obesity within ethnic minority groups in the UK (Cappuccio et al. 1997; Bhopal et al. 1999), particularly the high levels seen among women of Afro-Caribbean origin (Cappuccio et al. 1997; Pomerleau et al. 1999). Furthermore, this problem is not confined to adults. Recently, Whincup et al. (2002) demonstrated that the tendency to insulin resistance is already evident in South Asian children, and consequently prevention of obesity should begin in childhood and adolescence.

\section{Fat intake}

The results from epidemiological studies suggest that a diet that is high in saturated fat is linked with glucose intolerance and other metabolic disturbances such as elevated total cholesterol and LDL-cholesterol (Purnell \& Brunzell, 1997). These and other data have led to a recommendation to preferentially reduce saturated fat intake for the prevention of metabolic syndrome (Riccardi \& Rivellese, 2000). There is, however, some debate about the benefits of substituting carbohydrates, monounsaturated fat or polyunsaturated fat for saturated fat.

A possible alternative for replacing saturated fat in the diet is by promoting a low-fat high-carbohydrate diet. However, this recommendation has also been criticised on two bases. If dietary carbohydrate intake is increased, an increased amount of insulin is required to maintain glucose homeostasis. The second concern relates to the observation that low-fat high-carbohydrate diets are associated with an elevation in fasting triacyglycerols and a decrease in HDLcholesterol (Reaven, 1997). The alternative to substituting saturated fat with carbohydrates is to replace it with monounsaturated or polyunsaturated fat, or both. A metaanalysis by Gardner \& Kramer (1995) concluded that the changes in LDL- and HDL-cholesterol are similar when saturated fat is replaced either with carbohydrates or with monounsaturated fat or polyunsaturated fat, or both. Currently-available data suggest that isoenergetic diets high in monounsaturated fat or carbohydrates improve glucose tolerance to a similar extent when compared with a diet high in saturated fat (Purnell \& Brunzell, 1997).

\section{Fibre}

The finding by Lovejoy \& DiGirolamo (1992) that a low dietary fibre intake is correlated with diminished insulin sensitivity in lean and obese subjects has been followed by intervention studies which provide some evidence of the benefits of a high fibre intake. However, Jenkins et al. (2000) have demonstrated that these benefits are associated with intakes of viscous insoluble fibre rather than insoluble cereal fibre. The same authors have demonstrated that a high intake of low-glycaemic-index foods is not only associated with an improvement in insulin sensitivity, but also other disturbances characteristic of the metabolic syndrome.

\section{Diet and blood pressure}

High salt intake and increasing body weight both increase the risk of hypertension and, in addition, the Dietary Approaches to Stop Hypertension Collaborative Research Group have demonstrated that a diet rich in fruit, vegetables and low-fat dairy foods is able to lower both systolic and diastolic blood pressure independently of $\mathrm{Na}$ reduction and weight loss (Svetkey et al. 1999) A reduction in $\mathrm{Na}$ in combination with the 'dietary approaches to stop hypertension' diet had an additional lowering effect on blood pressure (Sacks et al. 2001).

\section{Folate}

Early studies demonstrated problems of low folate intake in South Asian women and a higher incidence of neural-tube defects in the Pakistani population compared with Caucasian women (Balarajan \& McDowell, 1984; Terry et al. 1985). However, there has been increasing interest in the role of this nutrient in relation to CHD.

McCully (1969) proposed homocysteine as an aetiological agent in the pathogenesis of vascular disease, and over the last decade at least ten large prospective cohort studies have published data demonstrating an association between homocysteine levels, CHD events and death (Tice et al. 2001). This finding is clearly of interest in relation to the documented low levels of vitamin $\mathrm{B}_{12}$ and folate intake in the diets of South Asians (Matthews \& Wood, 1984; Abraham et al. 1987; Dawson \& Waters, 1994) and the high rates of CHD. There is some evidence that high plasma concentrations of homocysteine may be an independent risk factor for $\mathrm{CHD}$ in men of Indian origin in the UK (Chambers et al. 2000), although at this stage the role of diet is unclear. However, the benefits of supplemental folic acid in lowering plasma homocysteine levels have been demonstrated on the basis of a meta-analysis of twelve clinical studies (Homocysteine Lowering Trialists Collaboration, 1998), and it has been proposed that supplementation with vitamins to lower homocysteine levels may provide a simple effective and inexpensive means of reducing CHD in Indian Asians in the UK. 
Table 2. Targets for dietary intervention in the South Asian and Afro-Caribbean communities in the UK

\begin{tabular}{lll}
\hline South Asians & Both communities & Afro-Caribbeans \\
\hline Vitamin D $\uparrow$ & Total energy $\downarrow$ & Salt $\downarrow$ \\
Fe $\uparrow$ & Total fat $\downarrow$ & Fruit and vegetables $\uparrow$ \\
$\begin{array}{l}\text { Folate and } \\
\text { Vitamin } \mathrm{B}_{12} \uparrow\end{array}$ & Monounsaturated & \\
& and polyunsatu- & \\
& rated fats $\uparrow$ & \\
& Fibre $\uparrow$ & \\
& Low-glycaemic-index \\
& foods $\uparrow$ & \\
& Obesity and weight & \\
& gain $\downarrow$ \\
\end{tabular}

$\uparrow$, Increase; $\downarrow$, decrease.

\section{What are the key points of dietary intervention?}

As Table 2 indicates there are a number of common dietrelated areas that might be targeted for intervention in both the South Asian and Afro-Caribbean communities. These target areas relate primarily to weight control and the prevention of insulin resistance. In addition, vitamin $\mathrm{D}, \mathrm{Fe}$, folate and vitamin $B_{12}$ might be the focus of particular health promotion activities in the South Asian community. For the Afro-Caribbean community there might be additional emphasis on salt intake and fruit and vegetable consumption.

The emphasis would vary according to age and gender groups. While 'healthy eating' advice for children might include all these elements, special emphasis would be appropriate concerning $\mathrm{Fe}$, vitamin $\mathrm{D}$ and folate in the pregnancy-related diet.

\section{What do we know about factors affecting diet?}

Any attempt to encourage dietary change in members of ethnic minorities must clearly take account of existing patterns and trends, and recognise the heterogeneity within groups and between groups. However, information on current eating habits and nutrient intake is at best variable. Government-funded studies such as the National Diet and Nutrition Surveys shed no light on the eating patterns and diets of members of ethnic minority groups, as they are not included in the surveys in sufficient numbers. The only exception has been the survey of infant feeding in Asian families (Thomas \& Avery, 1997). The data available indicates a picture of continuity and change. Few individuals reject the traditional foods of their cultural group completely, but the extent to which traditional eating habits are retained varies (Sheikh \& Thomas, 1994; Kassam-Khamis et al. 1996; Sharma et al. 1999). Studies consistently show that exposure to the host culture is a major factor influencing the extent of acculturation in eating habits. In addition, the types of change that occur follow common patterns, with the most rapid changes being made where innovation brings greater convenience and does not threaten strongly held religious views. Within every culture there are traditional ideas about the links between diet and health. Certain foods may be considered beneficial in
Table 3. Domains of psycho-social factors influencing dietary behaviour (adapted from Thomas, 1994)

\author{
Predisposing factors \\ Perception of risk \\ Belief in diet-disease connection \\ Perceived benefits of dietary change \\ Knowledge of sources of nutrients in food \\ Enabling factors \\ Barriers to dietary change \\ Ideals of body shape and size \\ Social support \\ Perceived norms \\ Change-related factors \\ Self-rated diet \\ Motivational interest in changing diet \\ Behavioural intentions to change diet \\ Perceived self efficacy \\ Experience with previous attempts to change
}

preventing and treating particular conditions. More generally, people from many groups share the idea that certain foods may have 'heating' or 'cooling' effects on the body, and that the key to wise eating is choosing foods that will keep the body 'balanced'. A number of studies have shown the persistence of such traditional ideas among people from a variety of ethnic backgrounds in the UK, particularly in relation to eating habits during pregnancy, following childbirth and in the management of diabetes. However, these beliefs seem to be less firmly held by younger members of ethnic minority communities.

\section{Understanding relevant health behaviours and identifying appropriate strategies}

It is well accepted that interventions designed to change eating patterns are more likely to be effective if they are based on an understanding of the factors that influence food choice. These choices usually result from a combination of factors, relating both to the individual and their social situation. Development of models to explain health and eating behaviour has identified a number of key factors that are summarised in Table 3. Acheson (1998) highlighted the need to develop services which promote greater awareness of health risks among members of ethnic minorities, and while some information is available (Health Education Authority, 2000), insights into many of these factors and the applicability of these models to members of ethnic minorities are still limited.

\section{Predisposing factors}

Some evidence certainly suggests that there may be different, and sometimes inappropriate, perceptions of risk among different population groups, both with regard to risk associated with group membership and at a more personal level.

Two small studies suggest that there may be a lack of awareness of the greater risk of CHD and diabetes in some 
groups within the South Asian community in the UK. In a study of forty mother and daughter pairs of Pakistani origin Siddiqi (1999) found that only half the mothers and daughters were aware that people of Pakistani origin were at greater risk of diabetes in comparison with whites, although rather more $(65 \%$ of the mothers and $72 \%$ of the daughters) were aware of the increased risk of CHD. Amongst Bangladeshi fathers and sons only $35 \%$ of the fathers and $50 \%$ of the sons considered that heart disease was more common among people of Bangladeshi origin compared with whites (Chowdhury, 1998).

A substantial number of both white (52\%) and AfroCaribbean $(61 \%)$ respondents felt at risk of having a heart attack or stroke in a study undertaken in South London by Dundas et al. (2001), and there was some indication that Caribbean respondents who were overweight were more likely than overweight white respondents to feel at risk.

The same study also found that black Caribbean (65.9\%) and black African (63.8\%) respondents were more likely than whites $(50 \%)$ to have a 'fatalistic' outlook, to believe that their behaviour would not influence their health. This finding is rather disappointing, since belief in the connection between a health behaviour and a particular outcome is widely regarded as an important prerequisite for changes in health behaviour.

Giving information is one of the most traditional elements of health promotion, and clearly a good understanding of the client group's current level of knowledge is essential to the design of any intervention programme. More information is needed about current levels of knowledge in order to facilitate planning of any future activities.

Among the respondents interviewed by Siddiqi (1999), three-quarters of the mothers believed that people of Pakistani origin develop diabetes as a result of eating too much sugar. While two-thirds of the mothers and daughters felt that a high-fat diet increased the risk of CHD in their community, about one-quarter felt that stress was the most important factor.

\section{Enabling factors}

Understanding the barriers to adopting change is always important in planning any intervention, and such barriers may take the form of practical aspects of behaviour change, or perceptions of what is possible. The perceptions that 'healthier' food may not taste as good, or that changes would be unacceptable to other family members are widespread in all groups of the population.

In addition, there may also be differences between communities. For example, it has been suggested that differing ideals of body shape and size may act as a barrier to weight control in some communities. Although morbidity rates for complications of obesity (non-insulin-dependent diabetes mellitus and hypertension) are higher in South Asian and Afro-Caribbean women than in Europeans, South Asian and Afro-Caribbean women in a study by Pomerleau et al. (1999) were less likely to rate themselves as overweight or to report that they were following a slimming diet. Of the three groups, South Asian women were the least likely to rate themselves as overweight at any given BMI. A similar finding was reported by Stevens et al. (1994). When comparing older women in the USA they found that black women were more likely to be satisfied with their weight and less likely to diet than white women. However, in a younger cohort in the UK studied by Dolan et al. (1990) there were no ethnic differences in concerns with body weight and shape, which suggests that perceptions of ideal body shape and size may be changing across generations.

The perceived norms of behaviour within any social group may affect the ease or difficulty of making changes, and it has been suggested that people from the South Asian community in the UK may come under considerable social pressure to eat more than they really would want to on social occasions, for fear that refusal would cause offence. In the study by Siddiqi (1999) it appeared that about three-quarters of mothers of Pakistani origin would not feel able to refuse food offered by an older relative, even when they felt full, although about half would refuse food offered by a younger relative or friend. Their daughters seemed much more willing to refuse in all cases, although still fewer than half would refuse an older relative (Table 4).

\section{Change-related factors}

Willingness to change is a key determinant of health behaviour, and one about which little is known in relation to aspects of diet amongst members of ethnic minorities. Similarly, the extent of success in previous attempts to change eating habits and the effects of this factor on willingness to make attempts are unknown. Health promotion is often designed to include elements of 'self-empowerment', to increase the individual's sense of self-efficacy in relation to health behaviours. However, as mentioned previously, work by Dundas et al. (2001) has indicated a tendency towards a 'fatalistic' approach among their study participants. Thomas et al. (1996), in a study of Asian and Caucasian schoolchildren aged 12-15 years, found that there was a tendency for South Asian boys, but not girls, to perceive themselves to be at the mercy of outside influences (external locus) more than Caucasian boys, and to believe

Table 4. Responses of forty mother and daughter pairs of Pakistani origin living in the UK to the question 'What should a person do if offered food when they already feel full?' (from Siddiqi, 1999)

\begin{tabular}{|c|c|c|c|c|c|c|}
\hline & \multicolumn{6}{|c|}{ Food offered by: } \\
\hline & \multicolumn{2}{|c|}{ Older relative } & \multicolumn{2}{|c|}{ Younger relative } & \multicolumn{2}{|c|}{ Friend } \\
\hline & Mothers \% & Daughters \% & Mothers \% & Daughters \% & Mothers \% & Daughters \% \\
\hline Refuse to eat & 27 & 45 & 52 & 72 & 52 & 72 \\
\hline Eat a little and leave the rest & 70 & 42 & 47 & 17 & 48 & 22 \\
\hline Eat all the food given & 3 & 13 & 1 & 11 & 0 & 6 \\
\hline
\end{tabular}


that keeping healthy was a matter of luck. Further work is needed to explore issues such as 'self-efficacy' and 'locus of control' among people of South Asian and Afro-Caribbean origin.

\section{Designing effective interventions}

There is a consensus that health-promotion programmes should be culturally sensitive if they are to be effective. Resnicow et al. (1999) propose that two dimensions require consideration. The first dimension, 'surface structure', involves matching intervention materials and messages to superficial observable characteristics of the target population, e.g. using people, places, language, music food, locations and clothing familiar to, and preferred by, the target audience. The second dimension is described as 'deep structure', which conveys salience and involves incorporating the cultural, social, historical, environmental and psychological forces that influence the target health behaviour in the proposed target audience. In order to develop such interventions the use of focus groups and pre-testing may be particularly valuable. (These focus groups may involve 'ethnic mapping', identifying aspects of a behaviour according to whether it is perceived to be associated with the target group or the white majority, starting with familiar items which subjects can clearly 'anchor' in relation to one or other cultural group, then moving on to consider aspects of the target behaviour.) In their conclusions the authors admit that there is very little objective evidence of the efficacy of a 'culturally sensitive' approach.

Hawthorne (2001) has described the positive effects of culturally-appropriate health education on glycaemic control and knowledge of diabetes in British Pakistani women with type 2 diabetes. However, illiterate women did not do as well as their literate peers, continuing to score less on knowledge parameters and showing no improvement in glycaemic control.

Communication is clearly a key issue in working with people whose first language is not English and those who are illiterate. An interesting development in Leicester has been the use of 'peer educators' as part of Project Dil, a community health promotion programme that aims to reduce risk factors for $\mathrm{CHD}$ amongst the South Asian community (Farooqi \& Bhavsar, 2001).

In fact, there is very little published evidence concerning the effectiveness of health promotion interventions generally in ethnic minority groups, and particularly in attempts to change diet. The majority of studies have been undertaken in the USA, and the Health Education Authority (1997) review of the effectiveness of interventions to promote healthy eating in people from ethnic minorities identified only two studies from the UK, both of which focused on supplementation of infant or toddler diets (Auckett et al. 1986; Daly et al. 1996).

Effective interventions may have a range of objectives. In addition to increasing an individual's knowledge (concerning personal risk, the relationship between diet and disease and better food choices), activities may include efforts to increase skills (food selection, food preparation,
Table 5. Key features of an integrated intervention programme

Use of appropriate mass media to 'raise consciousness', promote positive social norms and create an 'umbrella' for other activities Work with appropriate community groups (women's groups, youth groups etc.) designed to increase involvement and 'ownership', providing opportunities for active acquisition of knowledge, skills and positive attitudes to dietary change

Involvement of the primary care sector (with appropriate training of health professionals as well as support materials)

Involvement of local food retailers to stock and promote foods consistent with the desirable dietary changes

Involvement of local employers through occupational health and workplace catering

Liaison and coordination with school-based activities for young adults

Training of lay volunteers to support community activities, possibly including a home-visiting programme for women

Printed, audio-visual and other materials to support these activities Monitoring and evaluation

etc.) and strategies designed to promote environmental and practical changes that will facilitate adoption of different eating behaviours.

Furthermore, the individual's motivation and belief in their ability to change may need to be promoted, together with the creation of a supportive climate among other people who are important to them. Clearly, the need for information, skills training, motivation, social support and development of positive social norms will vary among members of different ethnic minority groups, and any intervention strategy will need to take this factor into account. Past experience suggests that effectiveness is enhanced by coordinated intervention, and that certain types of approach have particular strengths in relation to a given objective (Thomas, 1994; Health Education Authority, 2000). Table 5 identifies some of the key features that might be incorporated into a community-based nutrition intervention strategy.

\section{Conclusion}

In considering nutrition-related intervention strategies among members of ethnic minorities in the UK there are still more questions than answers. The questions are not only about the role of diet in health and disease, but also to an even greater extent about the beliefs and attitudes which underpin health behaviour in different groups, and the design of culturally-appropriate programmes to promote the adoption of optimal eating patterns.

\section{References}

Abraham R, Brown MC, North WR \& McFadyen IR (1987) Diets of Asian pregnant women in Harrow: iron and vitamins. Human Nutrition Applied Nutrition 41, 164-173.

Acheson D (1998) Independent Inquiry into Inequalities in Health. London: The Stationery Office.

Auckett M, Parks Y, Scott P \& Wharton B (1986) Treatment with iron increases weight gain and psychomotor development. Archives of Disease Childhood 61, 849-857. 
Balarajan R (1991) Ethnic differences in mortality from ischaemic heart disease and cerebrovascular disease in England and Wales. British Medical Journal 302, 560-564.

Balarajan R, Adelstein AM, Bulusu, L \& Shukula V (1984) Patterns of mortality among migrants to England and Wales from the Indian sub-continent. British Medical Journal 289, 1185-1187.

Balarajan R \& MacDowall M (1984) Mortality from congenital malformations by mother's country of birth. Journal of Epidemiology and Community Health 39, 102-106.

Barker DJP (1997) Maternal Nutrition, fetal nutrition and diseases in later life. Review. Nutrition 13, 243-249.

Bhopal R, Unwin N, White M, Yallop J, Walker L, Alberti KGMM et al. (1999) Heterogeneity of coronary heart disease risk factors in Indian, Pakistani, Bangladeshi and European origin populations a cross-sectional study. British Medical Journal 319, 215-220.

Cappuccio F, Cook DG, Atkinson RW \& Strazullo P (1997) Prevalence, detection and management of cardiovascular risk factors in different ethnic groups in South London. Heart 78, 555-563.

Chambers JC, Obeid, OA, Refsum H, Ueland P, Hackett D, Hooper J, Turner RM, Thompson SG \& Kooner JS (2000) Plasma homocysteine concentrations and risk of coronary heart disease in UK Indian Asian and European men. Lancet 355, 523-527.

Chowdhury F (1998) Health beliefs and knowledge about coronary heart disease: a comparison of Bangladeshi men and their sons. MSc Dissertation, King's College London.

Conley D \& Bennett NG (2001) Birth weight and income: Interactions across generations. Journal of Health and Social Behavior 42, 450-465.

CSO (1994) Office of Population Censuses and Surveys (1991) Ssocial Trends, p.26. London: HMSO.

Daly A, MacDonald A, Auckett A, Williams J, Wolf A, Davidson J \& Booth IW (1996) Prevention of anaemia in inner city toddlers by an iron-supplemented cow's milk formula. Archives of Disease in Childhood 75, 9-16.

Davey-Smith G, Hart C, Blane D, Gillis C \& Hawthorne V (1997) Lifetime socioeconomic circumstances and mortality; prospective observational study. British Medical Journal 314, 547-552.

Dawson DW \& Waters HM (1994) Malnutrition: folate and cobalamin deficiency. British Journal of Biomedical Science 51, 221-227.

Department of Health and Social Security (1980) Rickets and Osteomalacia. Report on Health and Social Subjects no. 19. London: H.M. Stationery Office.

Dolan B, Lacey JH \& Evans C (1990) Eating behaviour and attitudes to weight and shape in British women from three ethnic groups. British Journal of Psychiatry 157, 523-528.

Dundas R, Morgan M, Redfern J, Lemic-Stojcevic N \& Wolfe C (2001) Ethnic factors in behavioural risk factors for stroke: Implications for health promotion. Ethnicity and Health 6, 95-103.

Dunnigan MG, Glekin BM, Henderson JB, McIntosh WB, Sumner D \& Sutherland GR (1985) Prevention of rickets in Asian children: assessment of the Glasgow Campaign. British Medical Journal 291, 239-242.

Dunnigan MG, Paton JPJ, Haase S, McNichol GW, Gardner MD \& Smith CM (1962) Prevention of rickets in Asian children: assessment of Glasgow campaign. Scottish Medical Journal 7, 159.

Eaton PM, Wharton PA \& Wharton BA (1984) Nutrient intakes of pregnant Asian women at Sorrento Maternity Hospital, Birmingham. British Journal of Nutrition 77, 3-7.

Everson SA, Goldberg DE, Helmrich SP, Lakka TA, Lynch JW, Kaplan GA \& Salonen JT (1998) Weight gain and the risk of developing insulin resistance syndrome. Diabetes Care 21, 1637-1643.

Farooqi A \& Bhavsar M (2001) Project Dil: A co-ordinated primary care and community health promotion programme for reducing risk factors of coronary heart disease amongst the South Asian community of Leicester - experiences and evaluation of the project. Ethnicity and Health 6, 265-270.

Fuller KE (2000) Low birth weight infants: The continuing ethnic disparity and the interaction of biology and environment. Ethnicity and Disease 10, 432-445.

Gardner CD \& Kramer HC (1995) Monosunsaturated versus polyunsaturated dietary fat and serum lipids - a metaanalysis. Arteriosclerosis, Thrombosis and Vascular Biology 15, 1917-1927.

Harding S \& Balarajan R (2001) Longitudinal study of socioeconomic differences in mortality among South Asian and West Indian Migrants. Ethnicity and Disease 6, 121-128.

Hattersley L \& Creeser R (1995) Longitudinal Study 1971-1991: History, Organisation and Quality of Data. London: H.M. Stationery Office.

Hauner H (2002) Insulin resistance and the metabolic syndrome - a challenge of the new millennium. European Journal of Clinical Nutrition 56, Suppl.1, 525-529.

Hawthorne K (2001) Effect of culturally appropriate health education on glycaemic control and knowledge of diabetes in British Pakistani women with type 2 diabetes mellitus. Health Education Research 16, 373-381.

Health Education Authority (2000) Black and Ethnic Minority Groups in England: The Second Health and Lifestyles Survey. London: Health Education Authority.

Homocysteine Lowering Trialists Collaboration (1998) Lowering blood homocysteine with folic acid based supplements: meta analysis of randomised trials. British Medical Journal 316, 894-898.

Hyder N (1999) Maternal and infant nutrition: a comparison of Pakistani and Caucasian mothers in the UK. MPhil Dissertation, King's College London.

Jenkins DJA, Axelsen M, Kendall CWC, Augustin LSA, Vuksan V \& Smith U (2000) Dietary fibre, lente carbohydrates and the insulin-resistant diseases. British Journal of Nutrition 83, Suppl. 1, S157-S163.

Kassam-Khamis T, Thomas J \& Judd P (1996) Eating habits of second generation South Asia and in the UK. Scandinavian Journal of Nutrition 40, 84-87.

Kramer MS (1987) Determinants of low birth weight: Methodological assessment and meta-analysis. Bulletin of the World Health Organization 65, 663-737.

Kuh D \& Ben-Shlomo Y (editors) (1997) A Life Course Approach to Chronic Disease Epidemiology. Oxford: Oxford University Press.

Lawson MS \& Thomas M (1999) Vitamin D concentration in Asian children aged 2 years living in England: Population Survey. British Medical Journal 318, 28.

Lops VR, Hunter LP \& Lynn RD (1995) Anaemia in pregnancy. American Family Physician 51, 1189-1197.

Lovejoy J \& DiGirolamo M (1992) Habitual dietary intake and insulin sensitivity in lean and obese adults. American Journal of Clinical Nutrition 55, 1174-1179.

McCully KS (1969) Vascular pathology of homocysteinemia: implications for the pathogenesis of arteriosclerosis. American Journal of Pathology 56, 111-128.

McKeigue P \& Sevak L (1994) Coronary heart disease in South Asian communities. London: Health Education Authority.

Mather H \& Keen H (1985) The Southall Diabetes Survey. Prevalence of known diabetes in Asians and Europeans. British Medical Journal 291, 1081-1084. 
Matthews JH \& Wood JK (1984) Megaloblastic anaemia in vegetarian Asians. Clinical and Laboratory Haematology 6 , $1-7$.

Murphy J, Riordan P, Newcombe RG, Coles EC \& Pearson JF (1986) Relation of haemoglobin levels in first and second trimester to outcome of pregnancy. Lancet i, 992-995.

Nazroo JY (2001) South Asian people and heart disease: An assessment of the importance of socioeconomic position. Ethnicity and Disease 11, 401-411.

Pomerleau J, McKeigue PM \& Chaturvedi N (1999) Factors associated with obesity in South Asian, Afro-Caribbean and European women. International Journal of Obesity 23, 25-33.

Purnell JQ \& Brunzell JD (1997) The central role of dietary fat, not carbohydrate in the insulin resistance syndrome. Current Opinion in Lipidology 8, 17-22.

Raleigh VS (1997) Diabetes and hypertension in Britain's ethnic minorities: implications for the future of renal services. British Medical Journal 314, 209-213.

Raleigh VS \& Balarajan R (1995) The Health of Infants and Children among Ethnic Minorities. The Health of Our Children. London: H.M. Stationery Office.

Reaven GM (1997) Do high carbohydrate diets prevent the development or attenuate the manifestations (or both) of syndrome X? A viewpoint strongly against. Current Opinion in Lipidology 8, 23-27.

Resnicow K, Baranowski T, Ahluwalia JS \& Braithwaite RL (1999) Cultural sensitivity in public health: defined and demystified. Ethnicity and Disease 9, 10-21.

Riccardi G \& Rivellese AA (2000) Dietary treatment of the metabolic syndrome - the optimal diet. British Journal of Nutrition 83, Suppl. 1, S143-S148.

Robertson I, Glekin BM, Henderson JB, McIntosh WB, Lakhani A \& Dunnigan MG (1982) Nutritional deficiencies among ethnic minorities in the United Kingdom. Proceedings of the Nutrition Society 41, 243-256.

Roderick PJ, Jones I, Raleight VS, McGeown M \& Mallick N (1994) Population need for renal replacement therapy in Thames regions: ethnic dimension. British Medical Journal 309, 11111114.

Sacks FM, Svetkey LP, Vollmer WM, Appel LJ, Bray GA, Harsha D, Obarzanek E, Conlin PR, Mille ER, Simons-Morton DG, Karanja N \& Lin P-H (2001) Effects on blood pressure of reduced dietary sodium and the dietary approaches to stop hypertension (DASH) diet. New England Journal of Medicine 344, 3-10.

Scholl TO \& Hediger ML (1994) Anaemia and iron-deficiency: compilation of data on pregnancy outcome. American Journal of Clinical Nutrition 59, Suppl., 492S-501S.

Sharma S, Cade J, Riste L \& Cruickshank K (1999) Nutrient intake trends among African- caribbeans in Britain: a migrant population and its second generation. Public Health Nutrition 2, 469-476.

Sheikh N \& Thomas J (1994) factors influencing food choice among ethnic minority adolescents. Part 2. Nutrition and Food Science 5, 29-35.

Siddiqi N (1999) Knowledge, attitudes and beliefs of Pakistani women about overweight, obesity and related factors. MSc Dissertation, King's College London.

Sinaiko AR, Donahue RP, Jacobs DR \& Prineas RJ (1999) relation of weight and rate of increase in weight during childhood and adolescence to body size, blood pressure, fasting insulin and lipids in young adults. The Minneapolis Children's Blood Pressure Study. Circulation 99, 1471-1476.

Smith P \& Prior G (1996) Fourth National Survey of Ethnic Minorities: Technical Report. London: Social and Community Planning Research.

Steer PJ, Alam MA, Wadsworth J \& Welch A (1995) Relation between haemoglobin concentration and birth weight in different ethnic groups. British Medical Journal 310, 489-491.

Stevens J, Kumanyika SK \& Keil JE (1994) Attitudes towards body size and dieting:differences between elderly black and white women. American Journal of Public Health 84, $1322-1325$.

Svetkey LP, Simons-Morton D, Vollmer WM, Appel LJ, Conlin PR, Ryan DH, Ard J \& Kennedy BM (1999) Effects of dietary patterns on blood pressure. Sub group analysis of the Dietary Approaches to Stop Hypertension (DASH) randomized clinical trial. Archives of Internal Medicine 159, 285-293.

Terry PB, Bissenden JG, Condie RG \& Matthew PM (1985) Ethnic differences in congenital malformations. Archives of Disease in Childhood 60, 866-876.

Thame M, Wilks RJ, McFarlane-Anderson N, Bennett FI \& Forrester TE (1997) Relationship between maternal nutritional status and infant's eight and body proportions at birth. European Journal of Clinical Nutrition 51, 134-138.

Thomas J (1994) New approaches to achieving dietary change. Current Opinion in Lipidology 5, 36-41.

Thomas J, Regis D \& Balding J (1996) A comparison of health related behaviour of South Asian and Caucasian schoolchildren aged 12-15 years. Scandinavian Journal of Nutrition 40, Suppl. 31, 101-103.

Thomas M \& Avery V (1997) Infant Feeding in Asian Families Early Feeding Practices and Growth. A Survey Carried Out by the Social Survey Division of the Office of National Statistics on Behalf of the Department of Health. London: The Stationery Office.

Tice JA, Ross E, Coxson PG, Rosenberg I, Weinstein MC \& Hunink MG (2001) Cost effectiveness of vitamin therapy to lower plasma homocysteine levels for the prevention of coronary heart disease. Journal of the American Medical Association 286, 936-943.

Warnes T (1996) The age structure and ageing of the ethnic groups. In Ethnicity in the 1991 Census, vol. 1, pp. 151-177 [P Ratcliffe, editor]. London: H.M. Stationery Office.

Wharton PA, Eaton PM \& Wharton BA (1984) Subethnic variation in the diets of Moslem, Sikh and Hindu pregnant women at Sorrento Maternity Hospital, Birmingham. British Journal of Nutrition 52, 469-476.

Whincup PH, Gilg JA, Papacosta O, Seymour C, Miller G, Alberti KGMM \& Cook DG (2002) Early evidence of ethnic differences in cardiovascular risk: cross sectional comparison of British South Asian and white children. British Medical Journal 324, 635-638.

Working Party of the National Advisory Committee on Nutrition Education (1983) Proposals for Nutritional Guidelines for Health Education in Britain. London: Health Education Council. 